\title{
ENSINO DE GEOGRAFIA PARA SURDOS E OUVINTES: TRABALHANDO O CONCEITO DE PAISAGEM
}

\author{
Carla Mirelly Caetano Duarte \\ Aluna do $7^{\circ}$ período do Curso de Geografia da UFRN \\ Igor Silvestre dos Santos \\ Aluna do $7^{\circ}$ período do Curso de Geografia da UFRN \\ André Ferreira \\ Aluno do $7^{\circ}$ período do Curso de Geografia da UFRN
}

\section{Resumo}

Esse presente artigo tem o objetivo de discutir e exemplificar através de um relato de experiência como trabalhar o conceito de paisagem dentro de uma proposta inclusiva, com alunos surdos, através da utilização de uma maquete e quebra cabeça. Para tanto, inicialmente abordaremos algumas considerações sobre a proposta inclusiva, com base em alguns documentos oficiais educacionais, definindo o que é surdez e como a inclusão está inserida no cenário nacional. No outro capítulo discutiremos como a Paisagem está inserida dentro da Geografia Escolar, posteriormente iremos dissertar como foi nossa experiência e quais os

Palavras-Chaves: Educação Geográfica. Paisagem. Surdez.

\begin{abstract}
This article aims to discuss and exemplify through an experience report how to work the concept of landscape within an inclusive proposal with deaf students through the use of a model and puzzle. To do so, we will initially address some considerations about the inclusive proposal, based on some official educational documents, defining what is deafness and how inclusion is inserted in the national scenario. In the other chapter we will discuss how the Landscape is inserted within the School Geography, later we will discuss how our experience was and what didactic resources used.
\end{abstract}

Keywords: Geographic Education. Landscape. Deafness. 


\section{INTRODUÇÃO}

A Geografia Escolar deve proporcionar ao aluno ferramentas que possibilitem a compreensão do Espaço Geográfico. Nesse processo, a linguagem é fundamental, através dela é possível aprender elementos espaciais e interagir socialmente. Para o indivíduo surdo, isso pode ser limitado ou até mesmo impedido, na medida em que não existam adaptações na mediação dos processos de ensino e aprendizagem.

Os processos de ensino e aprendizagem de alunos com deficiência no Brasil são demarcados por três fases: segregação, integração e inclusão. Atualmente, a proposta inclusiva apresenta como premissa o direito de todos os alunos à educação. Nesse sentido, os alunos com deficiência devem aprender juntos com seus pares sem deficiência no ambiente escolar.

Nesse sentido, o objetivo desse trabalho é apresentar uma proposta de ensino do conceito de paisagem aos alunos do $6^{\circ}$ ano do Ensino Fundamental com ênfase para estratégias utilizadas para um aluno (a) surdo e alunos ouvintes. Para tal, apresenta-se a montagem de uma maquete, evidenciando a dicotomia paisagística (natural/cultural) e também de um quebra-cabeça para problematização dos elementos paisagísticos.

Portanto, inicialmente discutiremos sobre a surdez no contexto educacional, posteriormente apresentaremos a caracterização da turma e aluno (a) que hipoteticamente será aplicado, subsequentemente o relato de experiência, evidenciando a prática e resultados obtidos e, por fim, as considerações finais retomando de forma sintética o que já foi escrito, destacando algumas conclusões, e contribuições deste estudo para a compreensão da temática estudada.

\section{BREVES CONSIDERAÇÕES SOBRE A SURDEZ E O CONTEXTO EDUCACIONAL BRASILEIRO.}

A declaração de Salamanca (1994) preconiza um sistema educacional inclusivo. Nessa proposta, todos devem aprender juntos na escola, sendo a escola responsável por acolher e possibilitar o aprendizado e permanência de todos na escola, organizando-se para oferecer uma educação de qualidade para todos (BRASIL, 2008).

Nesse sentido, de acordo com as Diretrizes nacionais para educação especial na educação básica, os alunos surdos pertencem ao grupo dos que possuem dificuldade de comunicação e sinalização. Assimé assegurada, a acessibilidade dos conteúdos curriculares mediante a utilização de linguagens e códigos aplicáveis. Como indica o parágrafo $2^{\circ}$ do art, 12 da Resolução No 02/2001:

Deve ser assegurada, no processo educativo de alunos que apresentam dificuldades de sinalização diferenciadas dos demais educandos, a acessibilidade aos conteúdos curriculares mediante a utilização de linguagens e códigos aplicáveis, como o sistema braile e a língua de sinais, sem prejuízo do aprendizado da língua portuguesa, facultando-Ihes e às suas famílias a opção pela abordagem pedagógica que julgarem adequadas quando ouvidos os profissionais especializados em cada caso (BRASIL, 2001). 
A Resolução também expõe os diferentes serviços de apoio pedagógico especializado que deverão ser viabilizados pela escola, no art. $8^{\circ}$, inciso IV. Que são:

a) atuação colaborativa de professor especializado em educação especial;

b) atuação de professores-intérpretes das linguagens e códigos aplicáveis;

c) atuação de professores e outros profissionais itinerantes intra e Inter institucionalmente;

d) disponibilização de outros apoios necessários à aprendizagem, à locomoção e à comunicação. Além desses serviços, essa legislação prevê ainda a utilização de salas de recursos e, extraordinariamente, classes e escolas especiais como forma de cooperar para a inclusão de alunos no sistema educacional brasileiro.

Diante de todos os aparatos legislativos, nenhuma escola pode rejeitar um aluno deficiente, alegando não saber lidar ou atuar com eles, no caso da surdez a primeira providência que a escola deve tomar ao matricular um aluno surdo, é comunicar a secretaria de educação e solicitar a capacitação de seus professores e demais elementos da comunidade escolar (BRASIL, 2001).

De acordo com Novaes (2014), o surdo é a pessoa com limitação sensorial de forma total; enquanto, o deficiente auditivo é aquele que não possui surdez profunda, sua limitação sensorial é parcial. Conhecer e saber um pouco da deficiência do aluno é indispensável para o desenvolvimento de um bom trabalho. Na realidade escolar atual brasileira os deficientes auditivos e surdos têm ganhado espaço eles estão na escola, embora muitas vezes ainda de forma tímida e sorrateira, onde muitos conteúdos e habilidades necessárias para uma criança daquela determinada idade não desenvolvidas.

\section{O CONCEITO DE PAISAGEM NA GEOGRAFIA ESCOLAR}

Se tratando de Geografia, quando o aluno chega no $6^{\circ}$ do Ensino Fundamental II, o conceito de paisagem aparece como um dos conteúdos programáticos, ao ser uma categoria do Espaço, não estática que contribui para análise e compreensão espacial. Conforme Castrogiovanni, (2014, p. 83), a aparência da paisagem, portanto, é única, mas o modo como apreendemos poderá ser diferenciado. Embora na aparência as formas estejam dispostas e apresentadas de modo estático, não são assim por acaso. A paisagem pode-se dizer, é um momento do processo de construção do espaço.

Assim percebemos que a paisagem apesar de ser única, sua leitura possibilita várias interpretações, que estão diretamente relacionadas com as experiências e cosmovisão individual. Um dos conceitos bastante difundido de paisagem é do geógrafo Milton Santos, que afirma paisagem tudo aquilo que nós vemos, o que nossa visão alcança, é a paisagem. Esta pode ser definida como o domínio do visível, aquilo que a vista abarca. Não formada apenas de volume, mas também de cores, movimentos, odores, sons etc. (SANTOS, 1997, p.61).

É bem verdade, que se tratando de análise de Paisagem a visão é o primeiro sentido a ser utilizado e explorado, e o aluno surdo consegue ver. No entanto, entendemos que de acordo com esse conceito somente a visão não contempla a totalidade da complexidade paisagística, temos que envolver também os demais sentidos, para chegar mais próximo da realidade observada. 
$\mathrm{Na}$ tentativa de aproximar esse conceito aos alunos (surdos e ouvintes) a imagem é um recurso indispensável, no entanto ainda pode deixar dúvidas de sua aplicabilidade e definição. E principalmente o aluno surdo pode ficar prejudicado ao não ouvir e/ou entender as explicações orais do professor. E o conteúdo deve ser passado de forma igualitária aos diversos alunos. Expresso principalmente nos livros didáticos.

Com isso, observamos em um livro didático como o conceito de paisagem é tratado, que foi o Projeto Araribá de Geografia, do $6^{\circ}$ ano do ensino fundamental II, organizado pela Editora Moderna, tendo como editora responsável Sônia Cunha de Souza Danelli. Nesse livro é evidenciada a dicotomia paisagística, fazendo uma distinção entre paisagem natural e paisagem cultural, conforme figura 1.

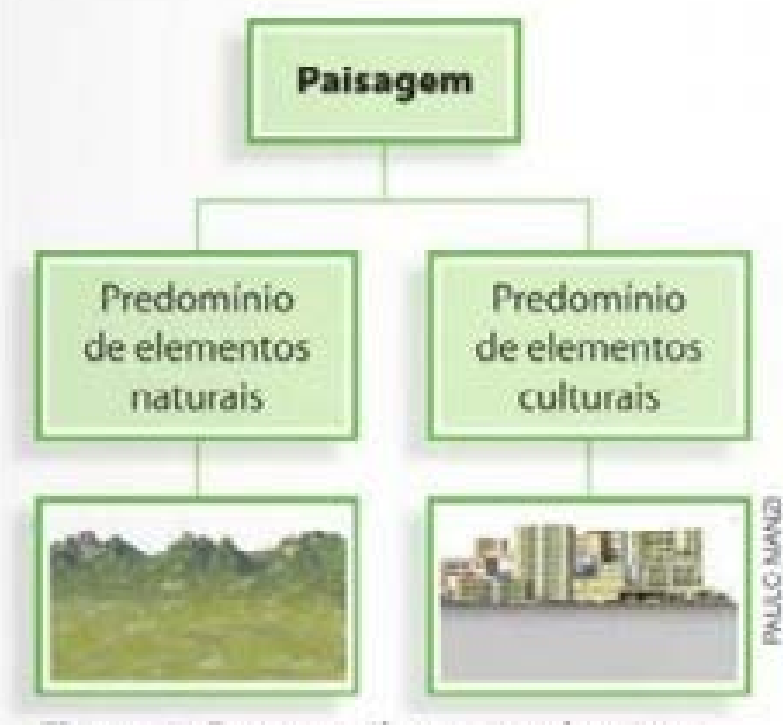

Figura 2. Esquema ilustrativo dos tipos de paisagem.
Figura 1: Esquema ilustrativo dos tipos de Paisagem.

Tomando como base esse livro, desenvolvemos duas formas de se trabalhar o conceito de paisagem na educação básica, que tanto engloba os alunos ouvintes quanto os alunos surdos. Que será exemplificado no próximo tópico.

\section{UM RELATO DE EXPERIÊNCIA: APLICANDO O CONCEITO DE PAISAGEM ATRAVÉS DE UM QUEBRA-CABEÇA E MAQUETE.}

\section{Quebra-Cabeça:}

0 quebra-cabeça forma uma imagem que contém elementos paisagísticos naturais e urbanos, a proposta é que os alunos em grupo montem o quebra-cabeça e consigam visualizar claramente a distinção paisagística entre paisagem natural e artificial, fazendo link com sua realidade. Posterior à montagem o professor deve entrar com suas explicações e construir o conhecimento em conjunto e não chegar e dar conceitos prontos, acerca do conceito de paisagem. Além de deixar aula mais interessante e dinâmica.

Esse quebra-cabeça foi impresso em uma gráfica em tamanho A3 e colado em uma folha de E.V.A. E pode ser feito com qualquer tipo de imagem. 


\section{Maquete:}

A ideia é que os alunos montem a maquete, com elementos paisagísticos (árvore, edificações, relevo etc.) sobre a base de isopor previamente prontos. A base apresenta dois planos de fundo, um lado com ruas e avenidas, representando a paisagem cultural e o outro com tonalidades verdes, representação da paisagem natural. Na sala o trabalho dos alunos é apenas montar, pois todos os objetos necessários serão levados construídos.

\section{ATIVIDADE NA PRÁTICA}

A atividade e pensada para alunos do $6^{\circ}$ ano do ensino fundamental II, buscando envolver tantos os ouvidos quanto os surdos. No entanto foi aplicada com uma aluna surda do $3^{\circ}$ ano "B" do ensino fundamental I da Escola Municipal Professora Francisca de Oliveira.

A aluna está sendo inserida no mundo bilíngue (libras/português), com auxílio de uma professora da Língua Brasileira de Sinais (LIBRAS). Hipoteticamente quando estiver no $6^{\circ}$ do Ensino Fundamental II não será fluente em libras, mas compreenderá em parte a língua de sinais. Na medida em que está sendo alfabetizada e seu acompanhamento futuro não é garantido.

0 trabalho foi desenvolvido no âmbito escolar com os estudantes de licenciatura em geografia, a professora de LIBRAS e uma aluna surda do $3^{\circ}$ ano. No primeiro momento é mostrada a aluna as paisagens diversas e suas diferenciações levadas impressas, incluindo paisagens da cidade do Natal, Amazônia, entre outras.

Logo após foi realizado a montagem do quebra-cabeça descrevendo a conceituação de paisagem natural e cultural. $O$ uso do quebra-cabeça foi utilizado como recurso didático no intuito de fomentar um ensino participativo permitindo um ensino-aprendizagem, numa relação de troca de saberes. A aluna se mostrou ansiosa, e curiosa na montagem do quebra- cabeça (ver figura 2 e 3). Com o auxiliou da professora de LIBRAS, de acordo com o surgimento do quebra-cabeça na mesa as paisagens, e suas diferenciações foram se realizando perguntas a aluna acerca da composição das paisagens. Diante de seu desenvolvimento da atividade, foi-se adequando os níveis de perguntas sobre a paisagem e seus elementos.

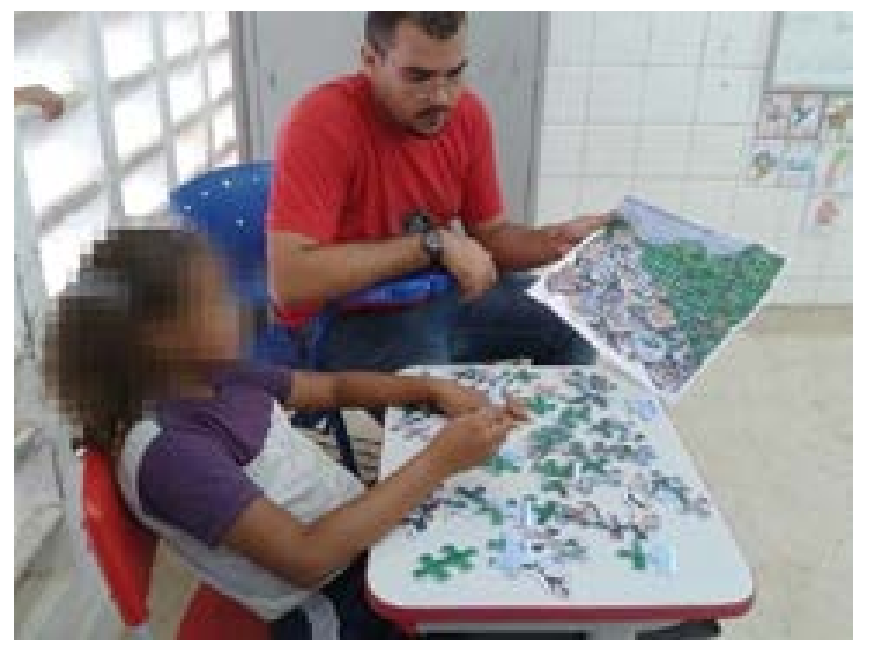

Figura 2: Primeiros passos para montagem do quebra cabeça.

Fonte: arquivo pessoal, 2016. 


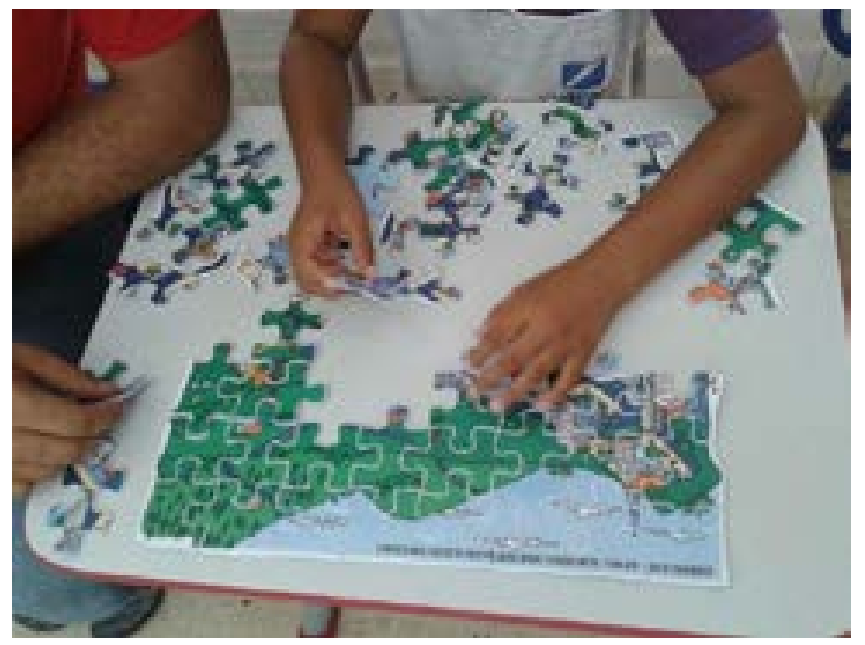

Figura 3: Montando o quebra cabeça.

Fonte: arquivo pessoal, 2016.

Levando em consideração suas limitações e entendimento a aluno, mostrou-se bastante desenvolvida para sua idade, por causa da sua vivência e exercício da observação. Suas percepções acerca da paisagem e diferenciações de seus elementos foram fonte de preparação para a segunda atividade da maquete.

Na segunda atividade da montagem de uma maquete buscou-se enfatizar ainda mais o que foi visto na primeira atividade. A construção desse recurso didático pelos alunos permite a compreensão do espaço que está sendo trabalhado, valorizando o conhecimento prévio dos mesmos. Sendo assim, compreendemos que:

A construção de maquetes geográficas, em classe, possibilita reconhecer, através da representação, a compreensão do espaço em que o aluno está inserido; permite integração entre professor $x$ aluno, entre prática x teoria; exige conhecimento do que (conteúdo) e como (forma) devemos representar; possibilita levantar hipóteses, correlacionar fatos, entre tantas alternativas do processo pedagógico. (NACKE e MARTINS, p. 10).

Nessa perspectiva, é compreensível que os signos funcionam como um sistema de informação cartográfica que alicerça uma maquete, permitindo identificar nesta, a forma e aquilo que ela representa, constituindo, portanto, um importante recurso didático e pedagógico, favorecendo a leitura, a análise e a interpretação do espaço geográfico.

No processo de ensino-aprendizagem, entende-se que incentivar o aluno a produzir maquetes permite uma participação maior deste no processo de aprendizagem, além de dar oportunidade ao educador para perceber o contexto sociocultural em que os estudantes estão inseridos. Portanto na atividade os elementos da paisagem natural e cultural estavam numa caixa à parte como:
- Árvores
- Rochas
- Edificações 
E na mesa estava apenas a base da maquete pintada com os lados definidos (campo e cidade). Foi pedido a aluna que fizesse a composição da maquete, e que colocasse na base da maquete os elementos de acordo com seu entendimento. Deste modo a composição de cada paisagem natural e cultural, foi se formando. Porém foram observados alguns momentos em que a aluna se sentiu confusa, neste momento foi se realizando perguntas novamente, como foi feito na primeira atividade do quebra-cabeça para relembrar alguns questionamentos. Desse modo a aluna pode entender melhor com a ajuda dos componentes do grupo, e a professora de LIBRAS, ver figura 4 e 5.
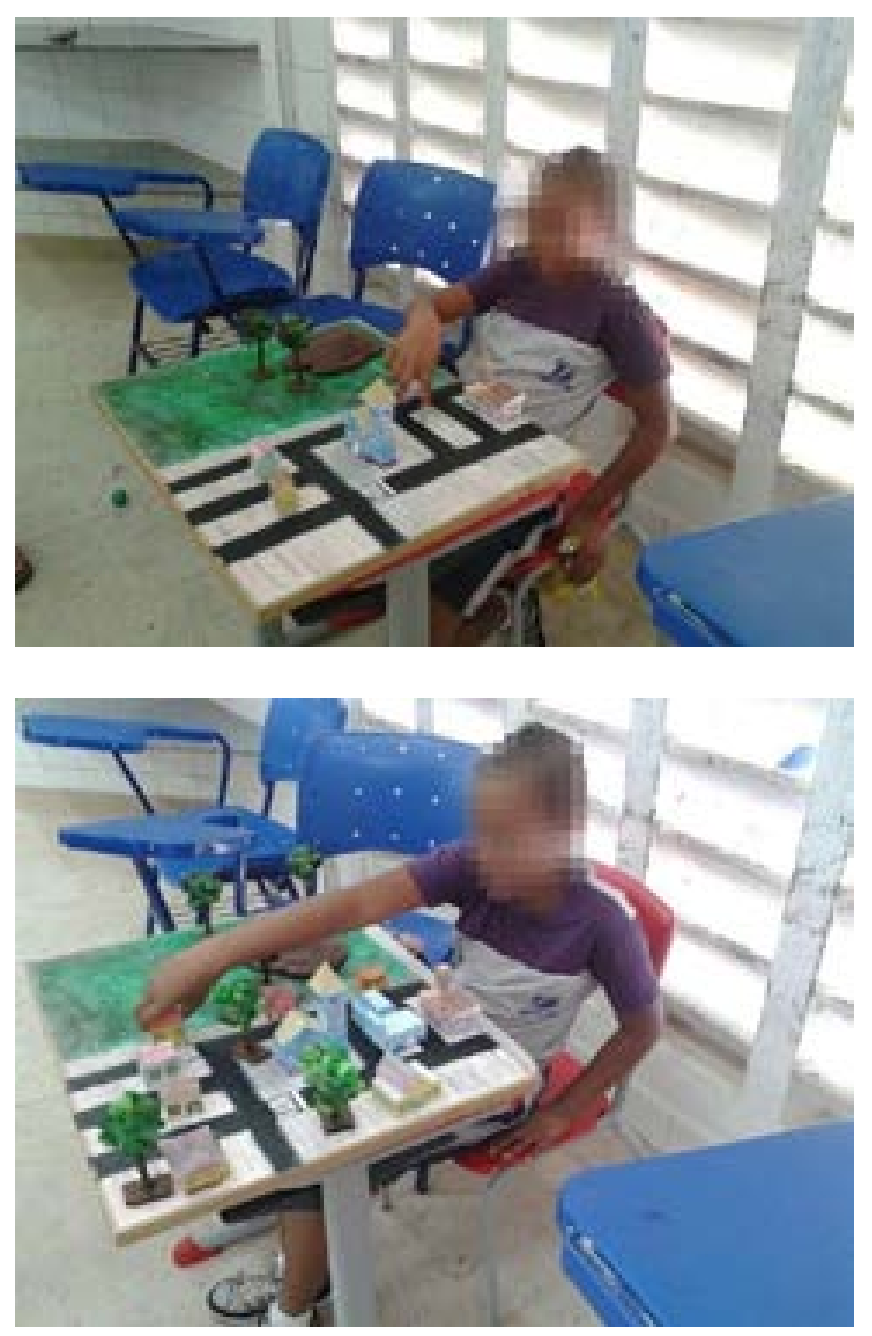

Figura 4: Primeiros passos para montagem da maquete.

Fonte: arquivo pessoal, 2016.

Figura 5: Montando a maquete.

Fonte: arquivo pessoal, 20

Com a finalização da maquete, e do quebra-cabeça, e diante de suas respostas durante a atividade, pode-se afirmar que foi extremamente positivo no momento em que o conteúdo proposto atingiu o objetivo desejado. A atividade desenvolvida pôde inferir que o ensino de geografia ao aluno surdo, enriquecido de imagens e elementos táteis como recurso concreto/didático é eficaz, no que tange o ensino e aprendizagem.

0 recurso didático, por sua vez, não tem a capacidade de garantir inteiramente a aprendizagem do aluno, mas desperta nesse um interesse maior na aula, pois oferece ao educando a oportunidade de trabalhar com elementos que o permitam ser protagonista na construção do conhecimento. É de extrema importância trabalhar os meios didáticos na perspectiva de estabelecer um diálogo na relação educador/educando, dando novos rumos ao ensino aprendizagem da Geografia, porém é necessário compreender que o objetivo ao se utilizar um recurso didático não é somente o novo, mas buscar metodologias que permitam uma abordagem mais lúdica referente ao conteúdo da disciplina. 


\section{CONSIDERAÇÕES FINAIS}

Diante do exposto podemos observar a importância do estudo da Paisagem para Geografia, e a sua adequação para o ensino de alunos especiais. Neste sentido podemos ressaltar a importância de novas metodologias para a eficácia na realização das práticas de ensino. Suas formulações dependem muito da estratégia dos docentes ou pesquisador estando atrelado com a realidade vivenciada.

A contribuição do conceito de paisagem é de suma importância não só para a Geografia como também para outras ciências. A complexidade e sua subjetividade fomentam uma profunda analise do tema, é preciso um mergulho profundo nas análises para que se possa verdadeiramente alcançar um resultado satisfatório e conseguir absorver todo o conhecimento acerca do tema proposto.

Vale salientar que atividade atingiu seus objetivos ficando a certeza que outras deficiências também poderão fazer uso da atividade com sucesso. 0 alcance poderá ser maior no momento que releituras possam ser feitas para um global alcance no âmbito do ensino especial.

\section{REFERÊNCIAS}

1. BRASIL. Ministério da Educação. Diretrizes nacionais para a educação especial na educação básica/ Secretaria de Educação Especial - MEC; SEESP, 2001. Disponível em:

<http://portal.mec.gov.br/seesp/arquivos/pdf/diretrizes.pdf.> Acesso: 15/05/2016

2. CASTROGIOVANNI, Antonio Carlos. Ensino de geografia: práticas e textualizações no cotidiano/ Estudar o lugar para compreender o mundo. Antonio Carlos Castrogiovanni (org.); Helena CopettiCallai, Nestor André Kaercher. - 11. ed. - Porto Alegre: Mediação, 2014. Acesso: 15/05/2016

3. LIMA, Daisy Maria Collet de Araujo. Educação infantil: saberes e práticas da inclusão: dificuldades de comunicação e sinalização: surdez. [4. ed.] / elaboração profa Daisy Maria Collet de Araujo Lima - Secretaria de Estado da Educação do Distrito Federal. [et. al.]. Brasília: MEC, Secretaria de Educação Especial, 2006. Disponível em:

<http://portal.mec.gov.br/seesp/arquivos/pdf/surdez.pdf>. Acesso: 17/05/2016.

4. NACKE, Sonia Mary Manfroi; MARTINS, Gilberto. A maquete cartográfica como recurso pedagógico no ensino médio. Disponível em: www.gestaoescolar.diaadia.pr.gov. br/.../File/.../artigo_sonia_mary_manfroi_nacke. Acesso: 15/05/2016.

5. NOVAES, Edmarcius Carvalho. Surdos: Educação, Direito e Cidadania. $2^{\mathrm{a}}$ ed. Rio de Janeiro. Editora: Wak, 2014.

6. RESOLUÇÃO CNE/CEB Nº 2, DE 11 DE SETEMBRO DE 2001. Disponível em: <http:// portal.mec.gov.br/cne/arquivos/pdf/CEB0201.pdf>. Acesso: 18/05/2016. 
7. SANTOS, Milton. Metamorfoses do Espaço Habitado: Fundamentos Teóricos e Metodológicos da Geografia. HUCITEC, São Paulo, 1997.

8. SILVA, Vládia; MUNIZ, Alexsandra Maria Vieira. GEOGRAFIA ESCOLAREOSRECURSOS DIDÁTICOS: O USO DAS MAQUETES NO ENSINO-APRENDIZAGEM DA GEOGRAFIA. Fortaleza: Revista Geosaberes, v. 3, n. 5, 06 jun. 2012. Semestral. Disponível em: <http:// www.geosaberes.ufc.br/seer/index.php/geosaberes/article/view/117/pdf506>. Acesso: 10/05/2016. 